Article

\title{
Preparation and Characterization of
} Tris(trimethylsiloxy)silyl Modified Polyurethane Acrylates and Their Application in Textile Treatment

\author{
Xuecheng Yu, Ying Xiong, Zhen Li and Hongding Tang * \\ Engineering Research Center of Organosilicon Compounds \& Materials, Ministry of Education, Sauvage Center \\ for Molecular Sciences, College of Chemistry and Molecular Sciences, Wuhan University, Wuhan 430072, China; \\ yuxuecheng1992@whu.edu.cn (X.Y.); yingxiong@whu.edu.cn (Y.X.); lizhen@whu.edu.cn (Z.L.) \\ * Correspondence: chhdtang@whu.edu.cn
}

Received: 13 June 2020; Accepted: 18 July 2020; Published: 22 July 2020

\begin{abstract}
Three series of silicone modified polyurethane acrylate (SPUA) prepolymers were prepared from dicyclohexylmethane-4, 4'-diisocyanate (HMDI), PPG1000, triethylene glycol (TEG), 2-hydroxyethyl acrylate (HEA), and multi-hydroxyalkyl silicone (MI-III) with tris(trimethylsiloxy)silyl propyl side groups. Their structures were confirmed by ${ }^{1} \mathrm{H}$ NMR, ${ }^{13} \mathrm{C}$ NMR, and Fourier transformed infrared (FTIR) analysis, and SPUA films were obtained by UV curing. The properties of films were investigated by attenuated total reflection (ATR)-FTIR, scanning electron microscopy (SEM), energy dispersive X-ray spectroscopy (EDS), water contact angle (WCA), thermogravimetric analysis (TGA), differential scanning calorimeter (DSC), water and hexane resistance, and tensile testing. The results showed that the structures and dosages of MI-III could influence the polymerization properties, surface properties, water and n-hexane resistance, and thermal and tensile properties of SPUA. For instance, the surface aggregation of tris(trimethylsiloxy)silyl propyl groups (even $\sim 2.5 \mathrm{wt} \%$ ) could endow SPUA films with less microphase separation, good hydrophobicity, lipophilicity, thermal stability, and mechanical properties. Interestingly, obvious regular winkles appeared on the surfaces of SPUAIII films, which are characterized by relatively high WCA values. However, relatively smooth were observed on the surfaces of SPUAIII films, which also exhibit lower water absorption ratio values. Furthermore, the ordinary cotton textiles would be transformed into hydrophobic and oleophilic textiles after treating with SPUA simply, and they were used in the oil/water separation study. Among them, consistent with water and hexane resistance analysis of SPUA films, SPUAII treated cotton textiles are characterized by relatively small liquid absorption capacity (LAC) values. Thus, phenyl groups and side-chain tris(trimethylsiloxy)silyl propyl groups are helpful to improve the hydrophobicity and lipophilicity of SPUA films. SPUAII-5 (even with $5 \mathrm{wt} \% \mathrm{MII}$ ) treated cotton textiles could efficiently separate the oil/water mixture, such as n-hexane, cyclohexane, or methylbenzene with water. Thus, this material has great potential in the application of hydrophobic treatment, oil/water separation, and industrial sewage emissions, among others.
\end{abstract}

Keywords: polyurethane acrylate; UV-curing; silicone; hydrophobicity; textile treatment; oil/water separation

\section{Introduction}

The water repellents of textiles are widely used in hydrophobic surface treatment, oil/water separation and textile finishing, among others [1,2]. Their hydrophobicity is usually achieved by using fluorine compounds [3], silicone compounds [4], and aliphatic compounds [5]. Among them, fluorine compounds are most widely used because of their ultralow surface energy. However, their 
practical applications are restricted by the poor low temperature resistance, high cost, and potential biological toxicity [6]. Meanwhile, silicone materials are well known not only for the low surface energy and hydrophobicity, but also for their excellent resistance to high and low temperatures, flexibility, good biocompatibility, and chemical inertness owing to the unique molecular structures $[7,8]$. Therefore, they have recently been applied to textile hydrophobic treatments [9-11]. However, the poor adhesion to the textile and poor mechanical properties of unmodified silicone materials still have to be improved [12].

Polyurethane (PU) is also widely used in textile treatment with many advantages such as durability and wrinkle resistance $[13,14]$. Compared with traditional moisture-sensitive PU, polyurethane acrylate (PUA), a category of photo-curable resin, not only exhibits good solubility, flexibility and mechanical properties, but also displays better storage stability, water resistance, solvent resistance, and lower melting viscosity [15-17]. Moreover, silicone modified polyurethane acrylate (SPUA) would be expected to combine the advantage of silicone and PUA materials $[18,19]$.

Nowadays, SPUA materials have attracted researchers' attention to develop their applications of hydrophobic textile treatment $[20,21]$. In these cases, hydroxyl-terminated polydimethylsiloxane (HO-PDMS-OH) were used to construct the main chains and acted as the hydrophobic ingredients (Scheme 1). Meanwhile, the massive silicone dosages are necessary in order to guarantee sufficient surface aggregation of PDMS segments for high hydrophobicity, as their movements were restricted by the polymer main chains. However, it would lead to serious microphase separation, decreased mechanical properties and high cost, when the ordered hard-segments domains (by hydrogen bonds) distribute in the nonpolar PDMS-segments domains [22-24]. In order to keep the balance between hydrophobicity and silicone loading, a workable way is to incorporate silicone into the side chains of SPUA.

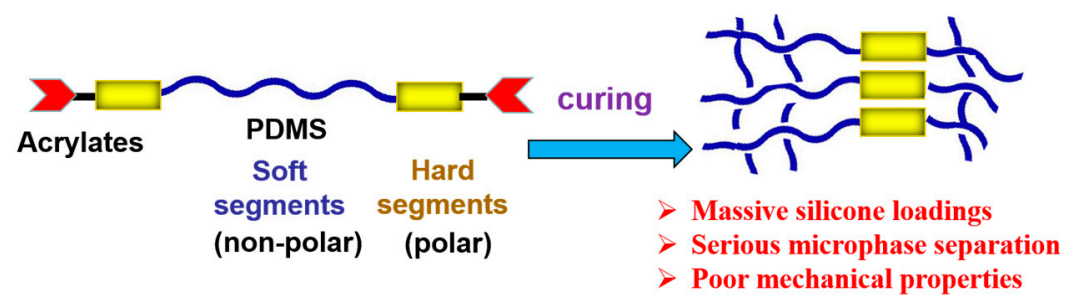

Scheme 1. The schematic diagram of main-chain silicone modified polyurethane acrylate (PUA). PDMS, polydimethylsiloxane.

From our previous research [25], side-chain tris(trimethylsiloxy)silyl propyl groups have been demonstrated to exhibit a definite surface migration trend in polyurethane films, which resulted in improved surface hydrophobicity and water resistance with only small silicone loadings. Following our continuing interesting, herein, three series of SPUA prepolymers (Scheme 2) with different silicone structures and contents were prepared from multi-hydroxylalkyl silicones (MI-III), triethylene glycol (TEG), polypropylene glycol (PPG1000), 2-hydroxyethyl acrylate (HEA), and dicyclohexylmethane-4, $4^{\prime}$-diisocyanate (HMDI). Then, SPUA films were obtained by the UV-radiation process. As expected, the SPUA films were characterized by good hydrophobicity. For instance, only $5 \mathrm{wt} \%$ of MI loading could change the WCA of the hydrophilic PUA from $79.9^{\circ}$ to $110.0^{\circ}$, and decrease the water absorption from $4.1 \%$ to $3.0 \%$. From energy dispersive $\mathrm{X}$-ray spectroscopy (EDS) analysis, the measured $\mathrm{Si}$ contents on the surface of cured SPUA films are almost double the calculated theoretical average values, indicating the definite surface migration trend of silicone. Moreover, the structures and dosages of introduce silicone could influence the polymerization properties, surface properties, water and n-hexane resistance, and thermal and tensile properties of SPUA. Interestingly, obvious regular winkles appeared on the surfaces of SPUAIII films, which are characterized by relatively high WCA values. However, relatively smooth surfaces were observed on the surfaces of SPUAII films, which also exhibit lower water absorption ratio values. Then, PUA and SPUA treated cotton textiles could be provided 
by dip coating and UV curing, and used in the study of oil/water separation (Scheme 3). Among them, SPUAII series (with Ph-groups) show relatively small liquid absorption capacity (LAC) values and are the best in the separation of oil/water mixture, such as n-hexane/water, cyclohexane/water, and methylbenzene/water, among others. Thus, these SPUA prepolymers have great potential applications in the hydrophobic treatment, oil/water separation, and industrial sewage emissions, among others.

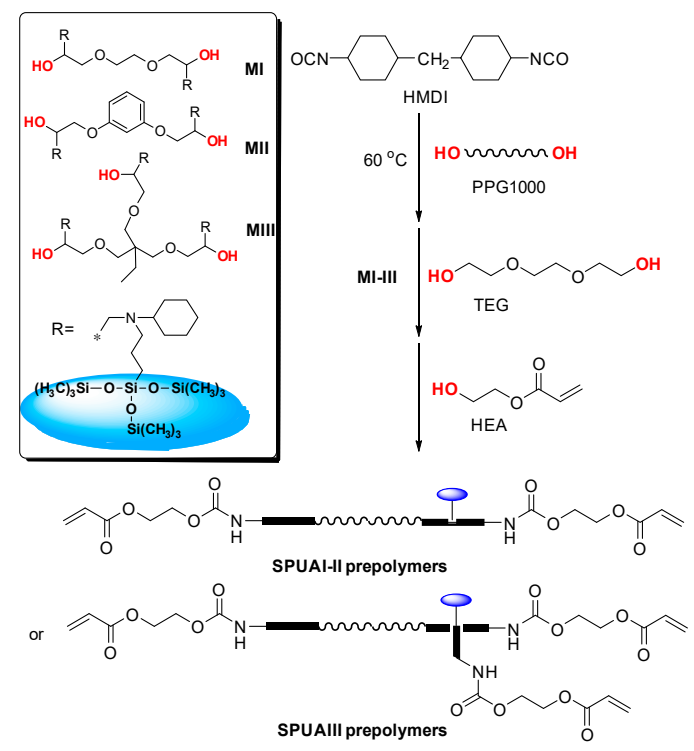

Scheme 2. Synthesis of silicone modified polyurethane acrylate (SPUA) prepolymers. MI, multihydroxylalkyl silicones; TEG, triethylene glycol; PPG1000, polypropylene glycol; HEA, 2-hydroxyethyl acrylate; HMDI, dicyclohexylmethane-4, 4'-diisocyanate.

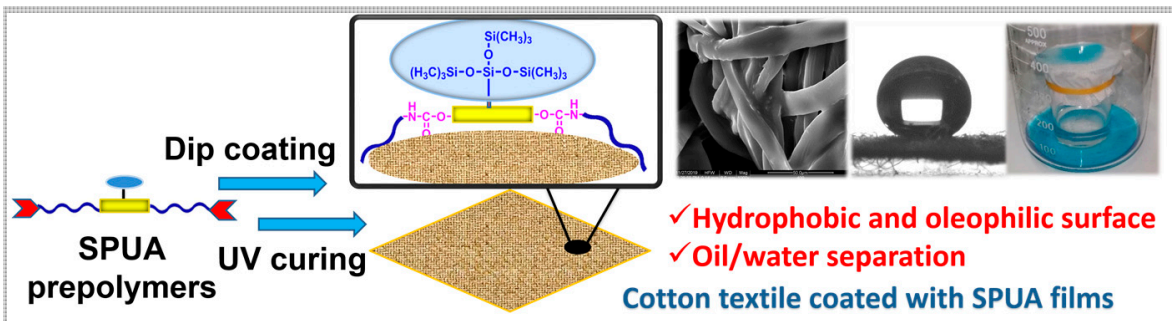

Scheme 3. The schematic illustration for the SPUA-treated cotton textiles.

\section{Experimental}

\subsection{Materials}

Polypropylene glycol (PPG1000, Mn 1000 g/mol), 2-hydroxyethyl acrylate (HEA), and 2-hydroxy-2-methylpropionphenone (HMPP, Darocur 1173) were purchased from Sigma-Aldrich Chemical (Yongin City, South Korea). Dibutyltin dilaurate (DBTDL), Ethyl acetate (EA) and triethylene glycol (TEG) were obtained from Sinopharm Chemical Reagent Co., Ltd. (Shanghai, China). Dicyclohexylmethane-4, 4' -diisocyanate (HMDI) was kindly offered free by Wanhua Chemical Group Co., Ltd. (Yantai, China). Ethyl acetate (EA) was purified by standard methods before use. The multi-hydroxylalkyl silicones with the tris(trimethylsiloxy)silyl propyl groups (MI-III) were prepared by the previously reported method [25]. The $100 \%$ plain-woven cotton textiles $\left(122 \mathrm{~g} / \mathrm{m}^{2}\right)$ were purchased from Weifang Qirong Textiles Co., Ltd. (Weifang, China), which was further purified by ultrasonic washing with distilled water and ethanol for $10 \mathrm{~min}$, respectively, and then dried in the oven at $80^{\circ} \mathrm{C}$. All other chemicals and solvents were used without further purification. 


\subsection{Instrumentations}

The viscosity of the prepolymers was measured by NDJ-5S rotational viscosimeter (Shanghai Ping Xuan Scientific Instrument Co., LTD., Shanghai, China) in mPa.s at $25^{\circ} \mathrm{C} .{ }^{1} \mathrm{H}$ NMR and ${ }^{13} \mathrm{C}$ NMR spectra were obtained with AVANCE AV-300 (Bruker BioSpin, Billerica, Massachusetts, USA) and recorded in $\mathrm{CDCl}_{3}$. The chemical structures of prepolymers were examined using FTIR spectroscopy in the Nicolet IS10 (Thermo Fisher Scientific, Waltham, MA, USA). The spectrums were recorded in the region of 400 to $4000 \mathrm{~cm}^{-1}$ at a resolution of $4 \mathrm{~cm}^{-1}$. Attenuated total reflection Fourier transformed infrared (ATR-FTIR) spectrums of UV-cured films were also recorded on Nicolet IS10, but with a compatible ATR module and germanium crystal at the incident angle of $45^{\circ}$. The spectra were recorded from 400 to $4000 \mathrm{~cm}^{-1}$ at a resolution of $4 \mathrm{~cm}^{-1}$ and 64 scans. Thermogravimetric analysis (TGA) was conducted using Setsys 16 (Aetaram, France) from 25 to $600{ }^{\circ} \mathrm{C}$ at $20^{\circ} \mathrm{C} / \mathrm{min}$ heating rate in nitrogen atmosphere. Differential scanning calorimeter (DSC) was performed on a DSC822 (Mettler Toledo, Zurich, Switzerland) from 100 to $-50^{\circ} \mathrm{C}$ at a cooling rate of $10^{\circ} \mathrm{C} / \mathrm{min}$ in nitrogen. Scanning electron microscopy (SEM) and energy dispersive $X$-ray spectroscopy (EDS) analysis were carried out using Quanta 200 (FEI NanoPorts, Hillsboro, OR, USA) at an accelerating voltage of $20 \mathrm{kV}$. The films and textiles were coated with gold to study the surface morphologies. The data of EDS were collected from a scanned region of about $100 \times 100$ square micrometres. Water contact angle $($ WCA) was performed on a G10 (KRUSS, Germany) instrument equipped with a camera through the sessile drop method, and the results were recorded one minute later. For each sample, at least three measurements were conducted and then the average value was calculated. Tensile tests were performed on SANS-CMT5 105 (Shenzhen Sans Testing Machine Co., LTD., Shenzhen, China) with a crosshead speed of $200 \mathrm{~mm} / \mathrm{min}$ $\left(\mathrm{L}_{0}=5 \mathrm{~mm}\right)$ at room temperature. Tests of at least three identical samples were conducted and the average value was calculated.

\subsection{Synthesis of Polyurethane Acrylate (PUA) Prepolymer}

In order to contrast with silicone modified counterparts, PUA prepolymer without silicone was prepared through the following procedure. A $250 \mathrm{~mL}$ of four-necked flask equipped with a condenser, a dropping funnel, a magnetic stirrer, and a device for argon flow was charged with $13.10 \mathrm{~g}$ (0.050 mol) of HMDI, $10.00 \mathrm{~g}(0.010 \mathrm{~mol})$ of PPG1000, $20.00 \mathrm{~g}$ of ethyl acetate, and $0.02 \mathrm{~g}$ of DBTDL, and the mixture was stirred at $60^{\circ} \mathrm{C}$ for $4 \mathrm{~h}$. Then, the mixture of $4.50 \mathrm{~g}(0.030 \mathrm{~mol})$ of TEG and $20.00 \mathrm{~g}$ of ethyl acetate (EA) was added dropwise at $60^{\circ} \mathrm{C}$ within $2 \mathrm{~h}$. After addition, the mixture was reacted at $70{ }^{\circ} \mathrm{C}$ for $1 \mathrm{~h}$ until the measured content of the residual -NCO groups reached the theoretical value (calculated from the recipe, $6.67 \times 10^{-4} \mathrm{~mol} / \mathrm{g}$ ) to provide the $-\mathrm{NCO}$ terminated prepolymer. Subsequently, $2.40 \mathrm{~g}$ $(0.020 \mathrm{~mol})$ of HEA was added into the -NCO terminated prepolymer and the mixture was kept at $60{ }^{\circ} \mathrm{C}$ for $4 \mathrm{~h}$ until the characteristic FTIR peak at $\sim 2264 \mathrm{~cm}^{-1}$ disappeared. This prepolymer was used for the preparation of PUA films without any further purification. FTIR (film, $\mathrm{cm}^{-1}$ ): 3328, 2968,

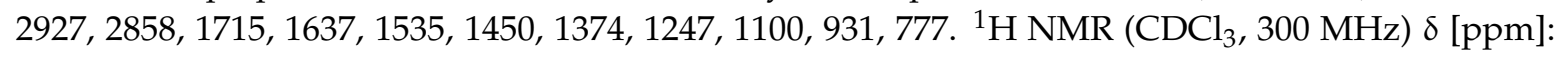
0.7-1.9 (N-CH- $\left.\mathrm{C}_{5} \mathrm{H}_{9}-\mathrm{CH}_{2}-\mathrm{C}_{5} \mathrm{H}_{9}-\mathrm{CH}-\mathrm{N}, \mathrm{CH}_{3}-\mathrm{CH}-\mathrm{O}\right), 3.1-3.8\left(-\mathrm{O}-\mathrm{CH}_{2}-\mathrm{CH}_{2}-\mathrm{O},-\mathrm{CH}_{2} \mathrm{CH}\left(\mathrm{CH}_{3}\right) \mathrm{O}-\right.$, $\mathrm{N}-\mathrm{CH}-), 4.2-4.4$ (-COO-CH$\left.{ }_{2},-\mathrm{COO}-\mathrm{CH}\left(\mathrm{CH}_{3}\right)-\right), 4.6-5.0(-\mathrm{NH}-\mathrm{CO}-\mathrm{O}-), 5.7-6.5\left(\mathrm{CH}_{2}=\mathrm{CH}-\right) .{ }^{13} \mathrm{C}$ NMR $\left(\mathrm{CDCl}_{3}, 75 \mathrm{MHz}\right) \delta$ [ppm]: 17.3, 27.9, 29.6, 32.0, 32.5, 33.5, 46.9, 50.3, 60.7, 63.6, 66.1, 69.7, 72.9, $75.2,128.1,131.2,155.6,165.9$.

\subsection{Synthesis of Silicone Modified Polyurethane Acrylate (SPUA) Prepolymers}

SPUA prepolymers were prepared according to Scheme 1. In order to maintain a consistent molar content of hard segments, the molar number of -OH (TEG and MI-III) is $0.03 \mathrm{~mol}$ in all experiments. Meanwhile, the molar number of HMDI or PPG1000 or HEA is consistent.

For clarity, the SPUAI with four different dosages of MI were prepared by the same procedure, but different recipes, which are listed in Table 1. The SPUA prepolymer prepared from MI with $5 \mathrm{wt} \%$ silicone is specified as SPUAI-5, and it is used as an example to demonstrate the preparation procedure 
for all the prepolymers. A $250 \mathrm{~mL}$ of four-necked flask equipped with a condenser, a dropping funnel, a magnetic stirrer, and a device for argon flow was charged with $13.10 \mathrm{~g}(0.050 \mathrm{~mol})$ of HMDI, $10.00 \mathrm{~g}$ $(0.010 \mathrm{~mol})$ of PPG1000, $20.00 \mathrm{~g}$ of EA, and $0.02 \mathrm{~g}$ of DBTDL, and the mixture was stirred at $60{ }^{\circ} \mathrm{C}$ for $4 \mathrm{~h}$. Then, the mixture of $4.50 \mathrm{~g}(0.030 \mathrm{~mol})$ of TEG, $1.57 \mathrm{~g}(0.0015 \mathrm{~mol})$ of MI, and $20.00 \mathrm{~g}$ of EA was added dropwise at $60{ }^{\circ} \mathrm{C}$ within $2 \mathrm{~h}$. After addition, the mixture was reacted at $70{ }^{\circ} \mathrm{C}$ for $1 \mathrm{~h}$ until the measured content of the residual $-\mathrm{NCO}$ groups reached the theoretical value (calculated from the recipe, $6.38 \times 10^{-4} \mathrm{~mol} / \mathrm{g}$ ) to provide the -NCO terminated prepolymer. Subsequently, $2.40 \mathrm{~g}$ $(0.020 \mathrm{~mol})$ of HEA was added into the -NCO terminated prepolymer and the mixture was kept at $60{ }^{\circ} \mathrm{C}$ for $4 \mathrm{~h}$ until the characteristic FTIR peak at $\sim 2264 \mathrm{~cm}^{-1}$ disappeared. The prepolymer was used for the preparation of SPUA films without any further purification. FTIR (film, $\mathrm{cm}^{-1}$ ): 3330, 2969, 2928, 2857, 1715, 1637, 1535, 1450, 1374, 1249, 1192, 1100, 1050, 844, 757. ${ }^{1} \mathrm{H}$ NMR $\left(\mathrm{CDCl}_{3}, 300 \mathrm{MHz}\right) \delta$ [ppm]: -0.1-0.1 (-Si-C $\left.\mathrm{CH}_{3}\right), 0.2-0.5\left(\mathrm{Si}-\mathrm{CH}_{2}-\right), 0.7-1.9\left(\mathrm{~N}-\mathrm{CH}-\mathrm{C}_{5} \mathrm{H}_{9}-\mathrm{CH}_{2}-\mathrm{C}_{5} \mathrm{H}_{9}-\mathrm{CH}-\mathrm{N}, \mathrm{CH}_{3}-\mathrm{CH}-\mathrm{O}\right.$, $\left.\mathrm{N}-\mathrm{CH}-\mathrm{C}_{5} \mathrm{H}_{10}\right), 3.1-3.8\left(-\mathrm{O}-\mathrm{CH}_{2}-\mathrm{CH}_{2}-\mathrm{O},-\mathrm{CH}_{2} \mathrm{CH}\left(\mathrm{CH}_{3}\right) \mathrm{O}-, \mathrm{N}-\mathrm{CH}-, \mathrm{N}-\mathrm{CH}_{2}-\right), 4.2-4.4\left(-\mathrm{COO}-\mathrm{CH}_{2}-\right.$, -COO-CH( $\left.\left(\mathrm{CH}_{3}\right)-\right)$, 4.6-5.0 (-NH-CO-O-), 5.7-6.5 $\left(\mathrm{CH}_{2}=\mathrm{CH}-\right) .{ }^{13} \mathrm{C} \mathrm{NMR}\left(\mathrm{CDCl}_{3}, 75 \mathrm{MHz}\right) \delta[\mathrm{ppm}]$ : $0.0,15.3,26.2,27.8,30.3,31.8,45.3,48.5,58.7,61.8,64.4,67.8,68.7,71.1,73.2,126.3,129.5,153.9,164.2$.

Table 1. The recipes for the preparation of polyurethane acrylate (PUA) and silicone modified PUA (SPUA)I. MI, multi-hydroxylalkyl silicones; TEG, triethylene glycol; PPG1000, polypropylene glycol; HEA, 2-hydroxyethyl acrylate; HMDI, dicyclohexylmethane-4, 4'-diisocyanate.

\begin{tabular}{llllllll}
\hline Sample & $\begin{array}{l}\text { MI } \\
(\mathbf{w t} \%)\end{array}$ & $\begin{array}{l}\text { HMDI } \\
\mathbf{( g )}\end{array}$ & $\begin{array}{l}\text { PPG1000 } \\
\mathbf{( g )}\end{array}$ & $\begin{array}{l}\text { TEG } \\
\mathbf{( g )}\end{array}$ & $\begin{array}{l}\text { MI } \\
\mathbf{( g )}\end{array}$ & $\begin{array}{l}\text { EA } \\
(\mathbf{g})\end{array}$ & $\begin{array}{l}\text { HEA } \\
(\mathbf{g})\end{array}$ \\
\hline PUA & 0 & 13.10 & 10.00 & 4.5 & - & 40.00 & 2.40 \\
SPUAI-5 * $^{*}$ & 5 & 13.10 & 10.00 & 4.27 & 1.57 & 40.00 & 2.40 \\
SPUAI-10 $^{*}$ & 10 & 13.10 & 10.00 & 4.03 & 3.28 & 40.00 & 2.40 \\
SPUAI-20 $^{*}$ & 20 & 13.10 & 10.00 & 3.46 & 7.24 & 40.00 & 2.40 \\
SPUAI-30 * & 30 & 13.10 & 10.00 & 2.75 & 12.11 & 40.00 & 2.40 \\
\hline
\end{tabular}

\subsection{Photopolymerization Experiments}

The light-induced photopolymerization experiments of PUA or SPUA prepolymers were carried out by real-time infrared spectroscopy (RT-IR). Different contents of HMPP were dissolved in the prepared PUA or SPUA prepolymers to form the photosensitive formulations. Then, they were deposited on $\mathrm{KBr}$ pellets in laminate for irradiation with a high-pressure mercury lamp (Ushio SH-250DB, Japan, I $=40 \mathrm{~mW} / \mathrm{cm}^{2}$ ). The evolution of the double-bond content was continuously monitored by real time FTIR spectroscopy (Nicolet IS 10, America) at $1650-1610 \mathrm{~cm}^{-1}$ [26]. The double-bond conversions (DC) were calculated from Equation (1) [27].

$$
\mathrm{DC}(\%)=\left(1-\frac{A_{\mathrm{X}, \mathrm{t}}}{A_{\mathrm{X}, 0}} \times \frac{A_{\mathrm{ST}, 0}}{A_{\mathrm{ST}, \mathrm{t}}}\right) \times 100 \%
$$

where $A_{0}$ and $A_{t}$ represent the areas of the IR absorption peaks of the functional groups of the sample before and after exposure during time $t$. The subscripts ST and $X$ represent the internal referential ester carbonyl peak at $1715 \mathrm{~cm}^{-1}$ and the double bond peak at $1650-1610 \mathrm{~cm}^{-1}$, respectively. For each sample, the series of real-time FTIR runs are repeated at least three times.

\subsection{Preparation of the UV-Cured Films}

HMPP (1.00 wt \%) was dissolved in the prepared PUA and SPUA prepolymers to form a uniform solution, which was then coated on the Teflon plate. After being placed at room temperature for $24 \mathrm{~h}$ to remove the solvent (EA), they were exposed for UV curing under a high-pressure mercury lamp $\left(40 \mathrm{~mW} / \mathrm{cm}^{2}\right.$, Ushio SH-250DB) for $600 \mathrm{~s}$ in $\mathrm{N}_{2}$ atmosphere. 


\subsection{Water and n-Hexane Absorption of the UV-Cured Films}

Water and n-hexane absorption of PU and SPU films were evaluated. The weighted cured films $\left(\mathrm{W}_{0}\right)$ were immersed in the distilled water or $n$-hexane at room temperature for $24 \mathrm{~h}$, followed by wiping off the surface water or n-hexane with a piece of filter paper, and then tested for weight $W_{1}$. For each sample, the experiments are repeated at least three times. The ratio (A) for absorbed water or $\mathrm{n}$-hexane in the cured film was calculated by Equation (2).

$$
A=\frac{\left(W_{1}-W_{0}\right)}{W_{0}} \times 100 \%
$$

\subsection{PUA- or SPUA-Treated Cotton Textiles}

Treated cotton textiles could usually be prepared by dip coating and UV curing (as shown in Figure 5A) [28]. Thus, cotton textiles $(10 \times 10 \mathrm{~cm})$ were first soaked in the solution composed of $2.0 \mathrm{~g}$ of the prepared PUA or SPUA prepolymers, $0.02 \mathrm{~g}$ of HMPP, and $8.0 \mathrm{~g}$ of ethyl acetate for $30 \mathrm{~s}$. After the textiles were taken out and then dried in an $80^{\circ} \mathrm{C}$ oven for 10 minutes, each side of the textiles was $\mathrm{UV}$ crosslinked in $\mathrm{N}_{2}$ atmosphere under a high-pressure mercury lamp ( $40 \mathrm{~mW} / \mathrm{cm}^{2}$, Ushio SH-250DB) for $600 \mathrm{~s}$ to provide the PUA- or SPUA-treated textiles.

\subsection{Liquid Absorption Capacity (LAC) of Untreated and Treated Cotton Textiles}

The liquid absorption capacity (LAC) of textiles could be determined according to standard ISO 9073-6:2003 “Textiles. Test methods for nonwovens. Part 6: Absorption" [29]. Textiles were cut into $10 \times 10 \mathrm{~cm}^{2}$ samples, and then weighed before and after immersing in water for $60 \mathrm{~s}$. For each sample, the experiments are repeated at least three times. The LAC values were obtained using Equation (3).

$$
L A C=\frac{m_{n}-m_{k}}{m_{k}} \times 100 \%
$$

where $m_{n}$ is the mass of wet textile $(\mathrm{g})$ and $m_{k}$ is the mass of dry sample (g).

\section{Results and Discussion}

\subsection{Synthesis and Characterization of PUA and SPUA Prepolymers}

As continuous interest, the multi-hydroxylalkyl compounds with tris(trimethylsiloxy)silyl propyl groups (MI-III) were used to construct photo-sensitive SPUA. Three series of SPUA prepolymers with different silicone contents were prepared. For comparison, PUA without silicone incorporated was also synthesized. In their structures (Scheme 1), polypropylene glycol (PPG1000) acts as the soft segments in polymers, and MI-III, TEG, and HMDI act as the hard segments. Meanwhile, the molar number of HMDI or PPG1000 or HEA is consistent in all series, which means the molar content of soft segments or hard segments is mainly consistent.

During the preparing process, the obvious viscosity differences between PUA and SPUA prepolymers were observed and the measured values are shown in Figure 1a. The viscosity of prepolymers could be affected by many factors, such as temperature, molecular weight, inter-chain force, crosslinking density, and solvent [30]. As can be seen, the viscosity of SPUAI-5 prepolymer (206 mPa.S) is much lower than that of PUA prepolymer (324 mPa.S). In contrast to PUA prepolymer, the loadings of solvents (EA) in all prepolymers are consistent $(40.00 \mathrm{~g})$, and the main-chain chemical structures of their prepolymers are maintained. Thus, only $5 \mathrm{wt} \%$ of silicone $(\sim 2.5 \mathrm{wt} \%$ side-chain tris(trimethylsiloxy)silyl propyl groups) could decrease the viscosity of SPUA prepolymers distinctly. The main reason is that the low-polarity side-chain silicone in SPUA decreases the formation of the inter-chain hydrogen bonds. The low viscosity should also be useful in practical applications as it could reduce the usage of volatile organic compounds (VOCs). However, the rigid phenyl groups 
in the SPUAII main chains and the higher crosslinking density in SPUAIII bring about the higher viscosities in comparison with the SPUAI prepolymers.

The NMR and FTIR spectra of PUA and SPUAI-5 are exampled to demonstrate the structures of the prepolymers. As can be seen from the NMR spectra of PUA prepolymer (ESI Figures S2 and S15) and SPUAI-5 prepolymer (ESI Figures S3 and S16), the peaks at 4.8 and $5.0 \mathrm{ppm}$ in ${ }^{1} \mathrm{H}$ NMR spectra and $156 \mathrm{ppm}$ in ${ }^{13} \mathrm{C}$ NMR spectra are ascribed to the protons and carbon in carbamate/urethane groups $(-\mathrm{NH}-\mathrm{CO}-\mathrm{O}-)$, demonstrating the reactions between $-\mathrm{NCO}$ and $-\mathrm{OH}$ groups [31]. The measured -NCO content reached the theoretical value of the prepolymer before adding HEA, showing the complete reactions between isocyanates and polyols. The peaks at 5.8, 6.1, and $6.4 \mathrm{ppm}$ in ${ }^{1} \mathrm{H} \mathrm{NMR}$ spectra and 166, 131, and $128 \mathrm{ppm}$ in ${ }^{13} \mathrm{C}$ NMR spectra result from the introduction of acrylate groups $\left(-\mathrm{O}-\mathrm{CO}-\mathrm{CH}=\mathrm{CH}_{2}\right)$. Meanwhile, the peaks at $0.0 \mathrm{ppm}$ in ${ }^{1} \mathrm{H}$ and ${ }^{13} \mathrm{C}$ NMR spectra of SPUAI-5 result from Si- $\mathrm{CH}_{3}$. In the FTIR spectra of PUA and SPUAI-5 prepolymers (ESI Figure S1a), the peaks at around $3330 \mathrm{~cm}^{-1}(\mathrm{~N}-\mathrm{H}), 1715 \mathrm{~cm}^{-1}\left(\mathrm{C}=\mathrm{O}\right.$ in acrylate) and $1535 \mathrm{~cm}^{-1}(\mathrm{~N}-\mathrm{H}$ and $\mathrm{N}-\mathrm{C}(\mathrm{O})$ in carbamate groups) and the disappeared characteristic absorption peak of $-\mathrm{NCO}\left(\sim 2264 \mathrm{~cm}^{-1}\right)$ confirm that the reaction between isocyanates and HEA is complete. Meanwhile the characteristic peaks of $\mathrm{C}=\mathrm{C}-\mathrm{CO}$ groups have been observed at about $1637 \mathrm{~cm}^{-1}$ [26]. Additionally, the peaks of about 844 and $757 \mathrm{~cm}^{-1}$ show the presence of $\mathrm{Si}-\left(\mathrm{CH}_{3}\right)_{3}$ in SPUAI- 5 spectrum. Thus, the prepolymers of PUA and SPUAI-5 were synthesized successfully.
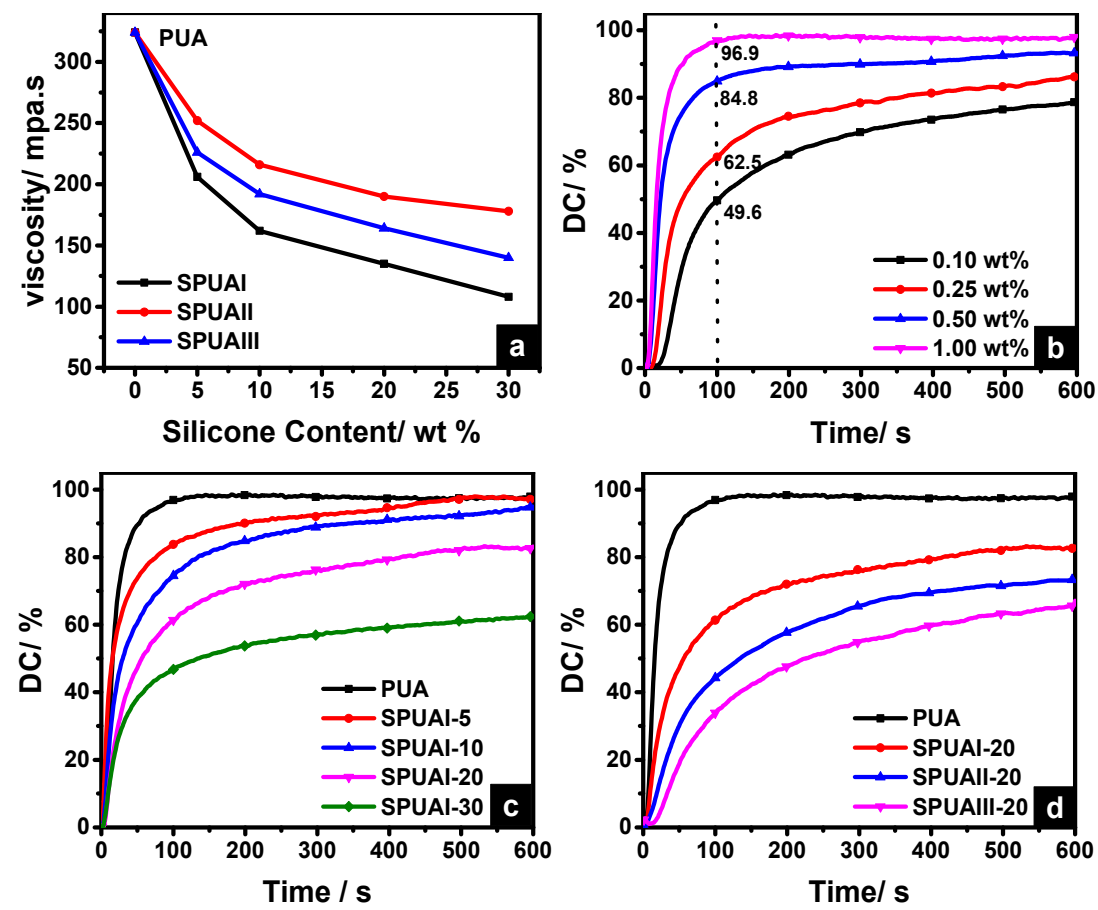

Figure 1. (a) Viscosity values of polyurethane acrylate (PUA) and silicone modified PUA (SPUA) prepolymers. Photopolymerization profiles of (b) PUA prepolymers initiated by 2-hydroxy-2methylpropionphenone (HMPP) with different contents, (c) PUA and SPUAI prepolymers initiated by $1.00 \mathrm{wt} \%$ of HMPP, and (d) PUA and SPUA prepolymers initiated by $1.00 \mathrm{wt} \%$ of HMPP. DC, double bond conversion.

\subsection{Photopolymerization Kinetics of PUA and SPUA Prepolymers}

In order to investigate the photopolymerization behaviors of PUA and SPUA prepolymers, real-time FTIR spectroscopy was used to monitor the double bond conversion (DC) under UV irradiation (Ushio SH-250DB, $40 \mathrm{~mW} / \mathrm{cm}^{2}$ ). A widely used commercial UV photo-initiator, HMPP, was used for photopolymerization. The impacts of HMPP contents to the photopolymerization behaviors of PUA prepolymers were investigated and the results are shown in Figure 1b. As can be 
seen, an obvious oxygen inhibition was observed when HMPP content is as low as $0.25 \mathrm{wt} \%$. With the increase of HMPP content, the degree of double-bond conversion (DC) and the rate of polymerization were improved. The DC could reach as high as $96.9 \%$ at $100 \mathrm{~s}$ when the content of HMPP arrived at $1.00 \mathrm{wt} \%$. Thus, $1.00 \mathrm{wt} \%$ of HMPP content was also used in the photopolymerization investigation in the following SPUA prepolymers. In the photopolymerization profiles of SPUAI prepolymers (Figure 1c), however, it was found that the DC decreased with the increase of the silicone content. The side-chain silicone groups are supposed to restrict the diffusion and mobility of terminal double bonds, indicating that uncured double bonds would be trapped in the polymeric networks [32]. Moreover, the decreased mass fraction of double bonds with the continuous increased silicone content would also lead to a lower DC value [33,34].

Furthermore, compared with SPUAII or SPUAIII series, SPUAI series exhibit a higher DC value (Figure 1d). The possible reason is that the rigid phenyl linking groups in SPUAII and the increased crosslinking density in SPUAIII make the main-chain movements harder than that of SPUAI [35], which is consistent with their viscosity differences. On the other hand, the crosslinking density of SPUAI-II decreases with the increase of silicone content. Therefore, high acrylate content and easy movement of polymer segments are helpful to obtain a high DC value in SPUA.

\subsection{Properties of PUA and SPUA Films}

ATR-FTIR is an efficient method to investigate the surface properties of polymer films. The ATR-FTIR spectra of PUA and SPUAI series of films are taken as examples and the results are presented in Figure 2a. From that, the intensity of absorption peaks at 842 and $756 \mathrm{~cm}^{-1}\left(\mathrm{Si}-\left(\mathrm{CH}_{3}\right)_{3}\right)$ and $1050 \mathrm{~cm}^{-1}$ (Si-O-Si) would increase, accompanied by the increase of silicone contents. Moreover, the hydrogen bonded carbonyl groups appear at $1699 \mathrm{~cm}^{-1}$, and the value is slightly lower than that of the free PU carbonyl groups $\left(\sim 1715 \mathrm{~cm}^{-1}\right)$ [36]. The carbonyl hydrogen bonding index (R) could be obtained by $\mathrm{A}_{1699} / \mathrm{A}_{1715}$ to describe the degree of the carbonyl groups participating in hydrogen bonding [37]. It could be found that $R$ would decrease with the increase of silicone contents, meaning the decrease of inter-chain hydrogen bonds and ordered hard segments in their films [38].

As can be seen from Figure $2 b$, the absorption peaks at around $1637 \mathrm{~cm}^{-1}$ for $-\mathrm{CH}=\mathrm{CH}_{2}$ in acrylates in SPUAI-30 prepolymer almost disappeared after photopolymerization, demonstrating the completion of UV curing on the film surfaces. Compared with the prepolymer, the film is characterized by a bigger $\mathrm{R}$ value (1.043), meaning the formation of hydrogen bonds during the UV-curing process.
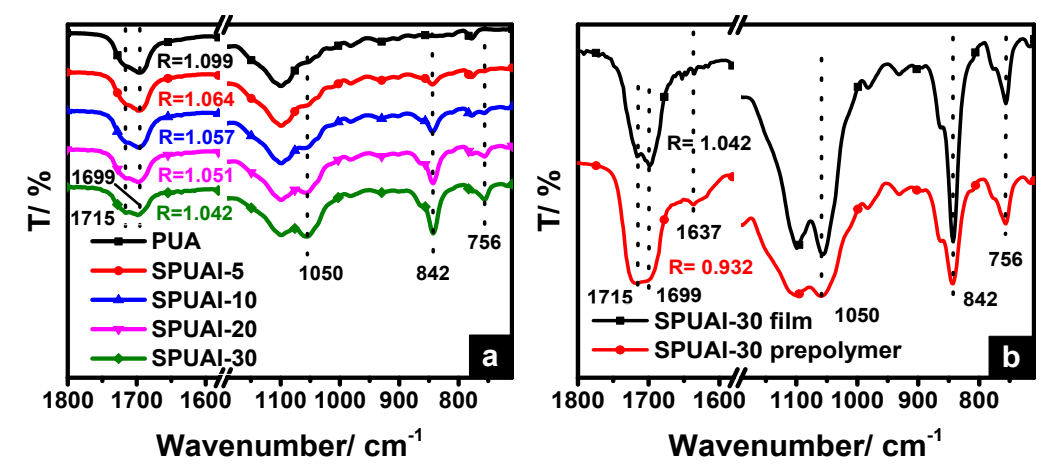

Figure 2. (a) Attenuated total reflection Fourier transformed infrared (ATR-FTIR) spectra for the PUA and SPUAI films, (b) ATR- FTIR spectrum of SPUAI-30 film and FTIR spectrum of its prepolymer.

For the further investigation, SEM and EDS analysis were used to evaluate the surface morphologies and the elemental contents of PUA and SPUA films. From the results in Table 2, a tiny amount of Si could also be measured in the pure PUA sample. The reason is that background noise peaks were calculated into the content of $\mathrm{Si}$, and the relative error limit of EDS analysis would be very big when the content of measured element content $<1.0 \mathrm{wt} \%$. Compared with the calculated average Si contents, the measured Si contents of SPUA surfaces are much higher. This should result from the polymer-air 
interface migration of silicone groups with low surface energy $[39,40]$. The silicon enrichment factor (F) can be obtained by the measured Si content divided by the calculated one to evaluate the surface migration trend of silicone, and a high F value demonstrates the high enriching efficiency [41]. As can be seen in Table 2, the F values of SPUAI and SPUAII are higher than those of SPUAIII with same silicone content, which could be explained in that the side-chain silicone in tri-functional MIII are restricted to the junction of main chains and hindered to migrate to the surface. The F values in SPUA decrease with the increase of silicone contents, implying that lower loading of silicone exhibits the stronger thermodynamic driving trend for surface migration [42,43].

The surface SEM images of PUA and SPUA films are shown in Figure 3. The PUA (Figure 2a) film shows a typical microphase separation morphology, in which many protrusions of hard-segment domains have dispersed in the soft segments [44]. Incorporation of only $5 \mathrm{wt} \%$ MI or MII into PUA could significantly decrease the microphase separation (Figure 3B,F), evidenced by the fact that only a little bit of agglomerations could be observed (inset). Meanwhile, the protrusions become more and more rare with the increase of silicone loadings (Figure 3B-I). The reason should be that the low polar side-chain silicone groups could efficiently decrease the formation of hydrogen bonds, which hinders the agglomeration of hard segments. Among three series, SPUII series (Figure 3F-I) display the smoothest surfaces with the least microphase separation, as the phenyl linking groups in MII are helpful to the improve the compatibility of different segments in SPUA.

Interestingly, regular wrinkles appear in SPUAI series (Figure 3D,E), and they are more obvious in SPUAIII series. However, almost no wrinkles are observed in PUA (the most serious microphase separation) and SPUAII (the less microphase separation) films. Thus, the degree of microphase separation could be an impact factor for the formation of this kind of wrinkles. On the other hand, the increased crosslinking, resulting from the photo-crosslinking and the introduction of trihydroxyalkyl MIII, brings about the volume shrinkage [45], which provides the force to form wrinkles. Therefore, the structure and loading of the silicone and the crosslinking density provide opportunities to adjust the surface morphology of SPUA films

Table 2. Surface silicon contents, thermal analysis, and WCA data for PUA and SPUA films.

\begin{tabular}{|c|c|c|c|c|c|c|c|}
\hline \multirow{2}{*}{$\begin{array}{c}\text { Samples } \\
\text { PUA }\end{array}$} & \multicolumn{2}{|c|}{$\begin{array}{l}\text { Si Content }{ }^{\text {a }}(w t \%) \\
\text { Measured Caculated }\end{array}$} & \multirow{2}{*}{$\frac{F^{\mathbf{b}}}{-}$} & \multirow{2}{*}{$\frac{\mathbf{T}_{\text {on }}{ }^{\mathbf{c}}\left({ }^{\circ} \mathbf{C}\right)}{287}$} & \multirow{2}{*}{$\frac{\mathbf{T}_{\mathbf{5 0}}{ }^{\mathrm{d}}\left({ }^{\circ} \mathbf{C}\right)}{355}$} & \multirow{2}{*}{$\frac{\mathbf{T}_{\mathrm{g}} \mathbf{e}\left({ }^{\circ} \mathrm{C}\right)}{-17.1}$} & \multirow{2}{*}{$\begin{array}{c}\operatorname{WCA}^{\mathbf{f}}\left(^{\circ}\right) \\
79.9(109.7)\end{array}$} \\
\hline & 0.25 & 0 & & & & & \\
\hline SPUAI-5 & 3.21 & 1.04 & 3.09 & 290 & 359 & -18.9 & $110.1(130.2)$ \\
\hline SPUAI-10 & 4.61 & 2.09 & 2.21 & 289 & 359 & -20.0 & $101.1(134.0)$ \\
\hline SPUAI-20 & 8.05 & 4.17 & 1.93 & 289 & 358 & -22.9 & 103.3 \\
\hline SPUAI-30 & 12.12 & 6.26 & 1.93 & 274 & 358 & -27.3 & 103.4 \\
\hline SPUAII-5 & 2.90 & 1.02 & 2.84 & 296 & 361 & -18.5 & $107.4(138.5)$ \\
\hline SPUAII-10 & 4.38 & 2.05 & 2.14 & 292 & 361 & -18.6 & $104.6(126.5)$ \\
\hline SPUAII-20 & 8.63 & 4.10 & 2.10 & 287 & 358 & -18.9 & $103.4(122.1)$ \\
\hline SPUAII-30 & 12.03 & 6.15 & 1.96 & 286 & 356 & -19.4 & $102.2(130.6)$ \\
\hline SPUAIII-5 & 2.24 & 1.05 & 2.13 & 295 & 367 & -16.8 & $107.4(129.0)$ \\
\hline SPUAIII-10 & 4.28 & 2.10 & 2.04 & 288 & 360 & -13.3 & 107.2 \\
\hline SPUAIII-20 & 8.04 & 4.20 & 1.91 & 288 & 359 & -14.4 & $110.1(132.9)$ \\
\hline SPUAIII-30 & 10.05 & 6.30 & 1.59 & 292 & 360 & -17.3 & 106.0 \\
\hline
\end{tabular}

${ }^{a} \mathrm{Si}$ content, the silicon atom content of the film surface, the measured values are measured by EDS analysis, and the calculated values are the average silicon contents from the recipes of the preparation. ${ }^{\mathrm{b}} \mathrm{F}$ is the silicon enrichment factor, $\mathrm{F}=$ (measured $w \mathrm{t} \%$ of silicon) / (calculated $\mathrm{w} t \%$ of silicon). ${ }^{\mathrm{c}} \mathrm{T}_{\mathrm{on}}$, the onset degradation temperature, refers to the temperature of $5 \%$ weight loss. ${ }^{\mathrm{d}} \mathrm{T}_{50}$ refers to the temperature of $50 \%$ weight loss. ${ }^{\mathrm{e}} \mathrm{T}_{\mathrm{g}}$, the glass transition temperature. ${ }^{\mathrm{f}}$ WCA, the water contact angle of films and treated cotton textiles (in parentheses).

Surface water-air contact angle is usually used to evaluate the hydrophobicity of material surface. According to Cassier theory and Wenzel model theory, the water contact angle (WCA) is determined by the surface chemical composition (intrinsic nature of hydrophobicity) and the surface geometrical microstructures (roughness) [46]. The WCA data of PUA and SPUA films are summarized in Table 2. 
The WCA of PUA film is measured to be $79.9^{\circ}$, implying its hydrophilic surface. The WCA of SPUAI- 5 film increases swiftly to $110.1^{\circ}$ with only $5 \mathrm{wt} \%$ MI loading ( $2.5 \mathrm{wt} \%$ side-chain tris(trimethylsiloxy)silyl propyl groups), mainly resulting from the efficient surface migration of hydrophobic silicone side groups. However, a further increase in MI loading to $10 \mathrm{wt} \%$ brings about $9^{\circ}$ decrease in WCA for SPUAI-10 $\left(101.1^{\circ}\right)$, mainly owing to a smoother surface. Furthermore, a slightly increased WCA in SPUAI-20 $\left(103.3^{\circ}\right)$ or SPUAI-30 $\left(103.4^{\circ}\right)$ is observed, further demonstrating that the micro roughness of film surface is also an important factor to the WCA [47,48]. Therefore, SPUAI-5 (Figure 3B), SPUAII-5 (Figure 3F), and SPUAIII series (Figure 3J-M) have relatively rougher surfaces and exhibit relatively higher WCA values among SPUA films.

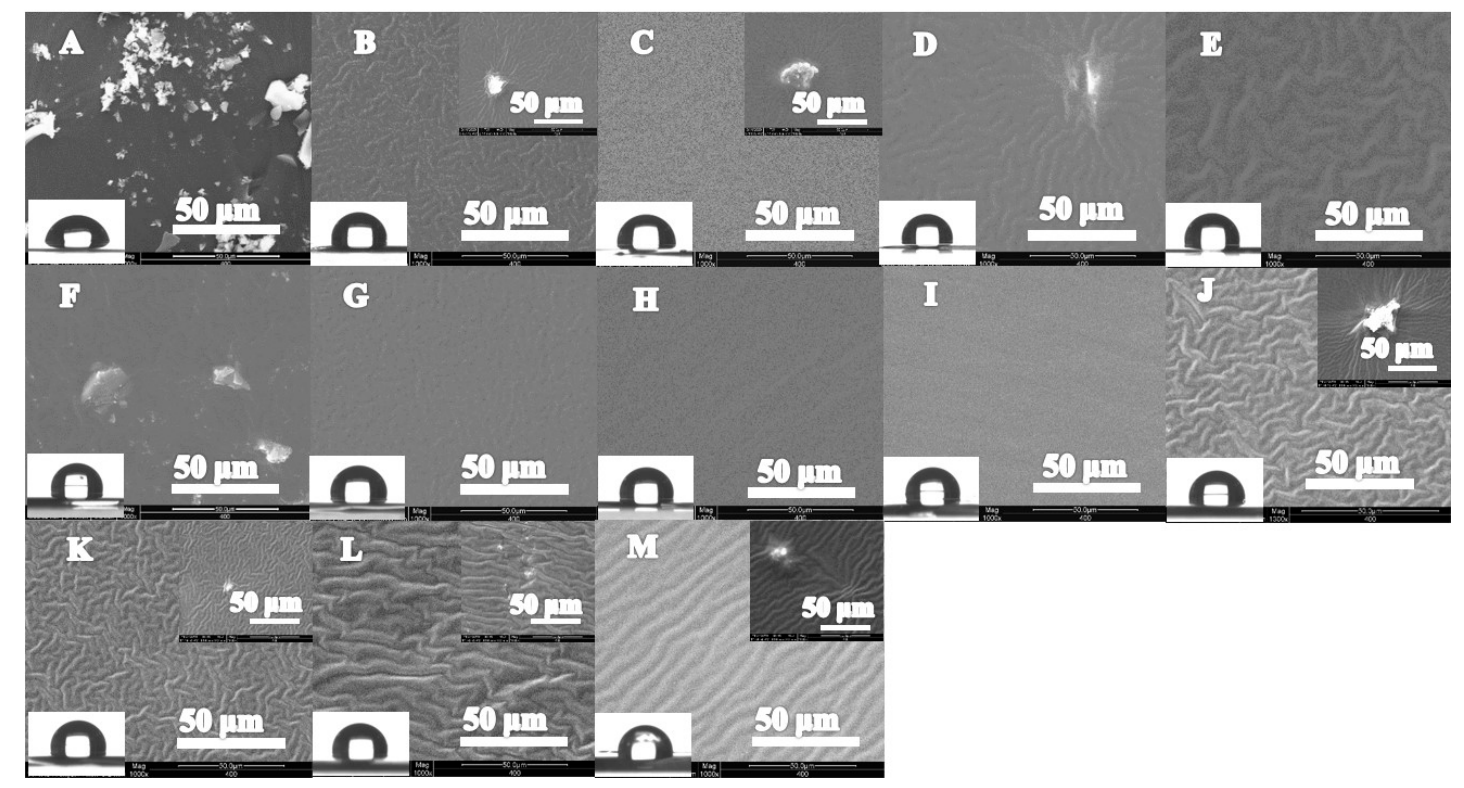

Figure 3. The representative scanning electron microscopy (SEM) images of PUA and SPUA films: (A) PUA, (B) SPUAI-5, (C) SPUAI-10, (D) SPUAI-20, (E) SPUAI-30, (F) SPUAII-5, (G) SPUAII-10, (H) SPUAII-20, (I) SPUAII-30, (J) SPUAIII-5, (K) SPUAIII-10, (L) SPUAIII-20, and (M) SPUAIII-30 (bottom left insets are the pictures of water contact angle (WCA) measurements and upper right insets are the pictures of microphase separation).

The thermal stability of PUA is also an important property for practical applications. Generally, its thermal stability depends on several factors such as structure, composition, crosslinking density, molecular weight, and inter-molecular forces [49-51]. The thermal stabilities of the PUA and SPUA films were investigated by TGA under $\mathrm{N}_{2}$ atmosphere (Figure S34), and the results are listed in Table 2. It is easy to find that the values of $\mathrm{T}_{\text {on }}$ (the temperature of $5 \%$ weight loss) for the SPUAI and SPUAII with low silicone contents (such as lower than $20 \mathrm{wt} \%$ ) are higher than that of PUA. In these cases, their main chains are almost the same, which means that the low loading of side chain tris(trimethylsiloxy)silyl propyl groups in PUA could increase its thermal stability. However, we also find that excessive silicone loadings (such as $30 \mathrm{wt} \%$ ) would decrease the thermal stability of SPUA, which should mainly result from the lower crosslinking density owing to the decreased content of acrylate and the lower DC values with the increase of silicone content, as mentioned before. It is noticed that the values of $\mathrm{T}_{50}$ for SPUA films are bigger than that of PUA, meaning that introduced silicone could enhance the thermal stability in a relatively high temperature and expand the application temperature range [52]. This may result from the protective char layer containing silica formed by thermal decomposed silicone [53]. Furthermore, compared with SPUAI series, SPUAII and SPUAIII series exhibit better thermal stabilities, which result from the phenyl groups incorporated in hard segments in SPUAII series and the increased crosslinking density in SPUAIII series. 
The glass transition temperature ( $\left.\mathrm{T}_{\mathrm{g}}\right)$ of PUA and SPUA films was obtained from DSC (Table 2). Generally, $\mathrm{T}_{\mathrm{g}}$ of polymers could be influenced by many factors, such as hydrogen bonds, soft and hard segments, the polymer chain motion ability, phase separation, cross-linking density, and so on [54]. From Table 2, SPUAI and SPUAII films exhibit lower $T_{g}$ values than that of PUA, and the $T_{g}$ values would decrease with the increase of silicone content. This should be attributed to the decreased hydrogen bonds caused by side-chain silicone groups [55], and the lower crosslinking density [56]. Among three SPUA series, the $\mathrm{T}_{\mathrm{g}}$ values of SPUAII and SPUAIII series are higher than those of SPUAI series, showing that increased rigid architecture and crosslinking density would restrict the motion of polymer chains and increase $T_{g}[57]$.

The mechanical properties of PUA and SPUA films are characterized by the strain and stress at break. As shown in Figure $4 a, b$, the stress at break of SPUAI and SPUAII films decreases with the increase of silicone content (Figure 4a), accompanied by a corresponding increase in strain at break (Figure 4 b). In comparison with PUA film, SPUAI-5 and SPUAII-5 films show slightly lower stress at break (Figure 4a). However, the further increase of the silicone content brings about the swiftly decreased stress at break.

The slight decrease of stress at break in SPUAI-5 and SPUAII-5 films should mainly result from the side-chain silicone groups, which decrease the formation of the hydrogen bonds [58]. Moreover, the less hydrogen bonds and lower crosslinking density lead to the swiftly decreased tensile strength and increased elongation at break with the increase of silicone content $[59,60]$. As aforementioned, the SPUAIII series possess extra increased crosslinking density by the introduction of tri-functional MIII. Therefore, SPUAIII series display relatively high tensile stress and low strain at break among three series.
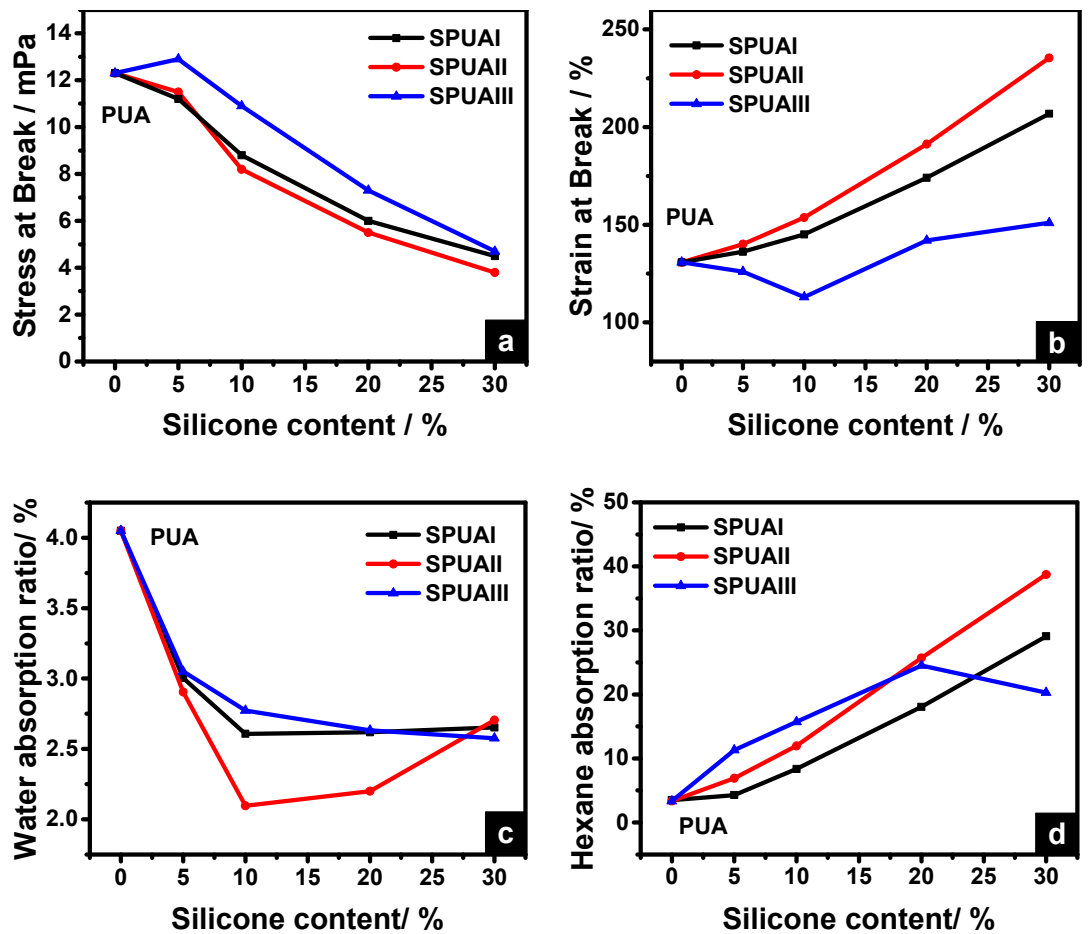

Figure 4. The (a) stress and (b) strain at break and (c) water and (d) n-hexane absorption ratio of PUA and SPUA films.

In order to evaluate the water and hexane resistance of PUA and SPUA films, their water and n-hexane absorption ratios are summarized in Figure 4c,d. As seen from Figure 4c, the water absorption ratios of SPUAI and SPUAII series decrease at first, and then increase with the increase of the silicone contents, and the smallest value is obtained when the silicone content is $10 \mathrm{wt} \%$ in each series. As mentioned before, the crosslinking density of SPUAI-II series would decrease with the increase of 
silicone content, which should lead to higher water absorption of films. Meanwhile, a high silicone content causes the more hydrophobic surface and brings about lower water absorption [61]. Therefore, the hydrophobic silicone plays a leading role in water resistance when the silicone content is lower than $10 \mathrm{wt} \%$. With the further increased silicone content, the decreased crosslinking density plays a leading role. Furthermore, the lowest water absorption ratio of SPUII-10 in three series of SPUA implies that the phenyl linking groups are helpful to improve water resistance.

However, the n-hexane absorption ratios of SPUAI-II series increase with the increased silicone content, which should be attributed to the increased low polar silicone groups and the decreased crosslinking density. Interestingly, the hexane absorption ratio of SPUAII series is higher than that of SPUAI series accordingly, which should result from the oleophilic phenyl groups and lower crosslinking density of SPUAII series than that of SPUAI series.

For SPUAIII series, the water absorption continuously decreases with the increase of MIII content, resulting from the continuously increased silicone loading and crosslinking density. Among SPUAI-III series, the highest water absorption ratios of SPUAIII series are observed when the silicone content is lower than $20 \mathrm{wt} \%$. This should be because the surface silicone contents of SPUAIII films are lower than those of SPUAI and SPUII films from EDS analysis. With the further increased silicone loadings, crosslinking density plays a leading role and SPUIII-30 give the lowest value compared with SPUI-30 and SPUII-30. However, the n-hexane absorption ratios of SPUAIII series first increase and then decrease with the increase of silicone content, in which SPUAIII-30 silicone content showed a lower absorption ratio because the higher crosslinking density plays a more important role.

\subsection{SPUA-Treated Cotton Textiles}

As aforementioned, SPUA films exhibit distinct water resistance and surface hydrophobicity. Therefore, their applications in surface hydrophobic treatment of cotton textiles were carried out. The treated cotton textiles could be obtained by dip coating and UV curing, and the WCA data of them are listed in Table 2. The WCA of the cotton textile treated with PUA $\left(109.7^{\circ}\right)$ is much higher than that of the hydrophilic PUA film $\left(79.9^{\circ}\right)$, mainly because of the surface roughness of cotton textiles (Figure 5B) [62]. Moreover, the WCAs of cotton textiles treated with SPUA are as high as $\sim 130^{\circ}$. As can be seen from Figure 5B-E, the SEM image of the cotton textile treated with SPUA shows that the cotton fibres are coated with polymer films evenly and sufficiently. This kind of cover could not only bring about the hydrophobic silicone groups aggregated on the surface of coated SPUA films (Figure 5B-E), but also maintain the micro-roughness of cotton textiles [62].

However, the n-hexane droplets (dyed yellow in Figure 6A) could completely wet the treated cotton textiles. That is to say, SPUA-treated cotton textiles show the hydrophobic and oleophilic properties, and may have potential application in oil/water separation. Thus, the oil/water separation experiments of the treated cotton textiles were carried out. As a model device for oil/water separation (Figure 6B(a)), the treated cotton textile was covered on a small beaker, which was placed in a bigger beaker [12]. If the oil could penetrate through the treated textile, but the water could not, this apparatus could separate oil/water effectively. Then, the mixture of n-hexane and the dyed water with methylene blue was drained slowly along a glass rod onto the covered cotton textile on the small beaker. Lots of water accompanied by n-hexane penetrated into the small beaker (Figure $6 \mathrm{~B}(\mathrm{~b})$ ) when PUA-treated cotton textile was used. In the cases of SPUAI-5- and SPUAIII-5-treated cotton textiles, only a little bit of water leaked into the small beaker (Figure $6 \mathrm{~B}(\mathrm{c}, \mathrm{g})$ ). Moreover, no water went through the SPUAII-5-treated cotton textile (Figure $6 \mathrm{~B}(\mathrm{e})$ ), but all of n-hexane penetrated through it. Thus, it could realize the oil/water separation effectively. Furthermore, the wettability of treated cotton textiles was investigated by LAC (Figure 6C). The bigger LAC value of PUA-treated cotton textile should result from the strong polar groups [63]. Consistent with previous water and hexane resistance analysis of SPUA films, SPUAII-treated cotton textiles are characterized by relatively small LAC values (Figure 6C). The possible reason is that oleophilic phenyl groups and nonpolar silicone groups are helpful for the water resistance and the passage of oil, as mentioned before. 


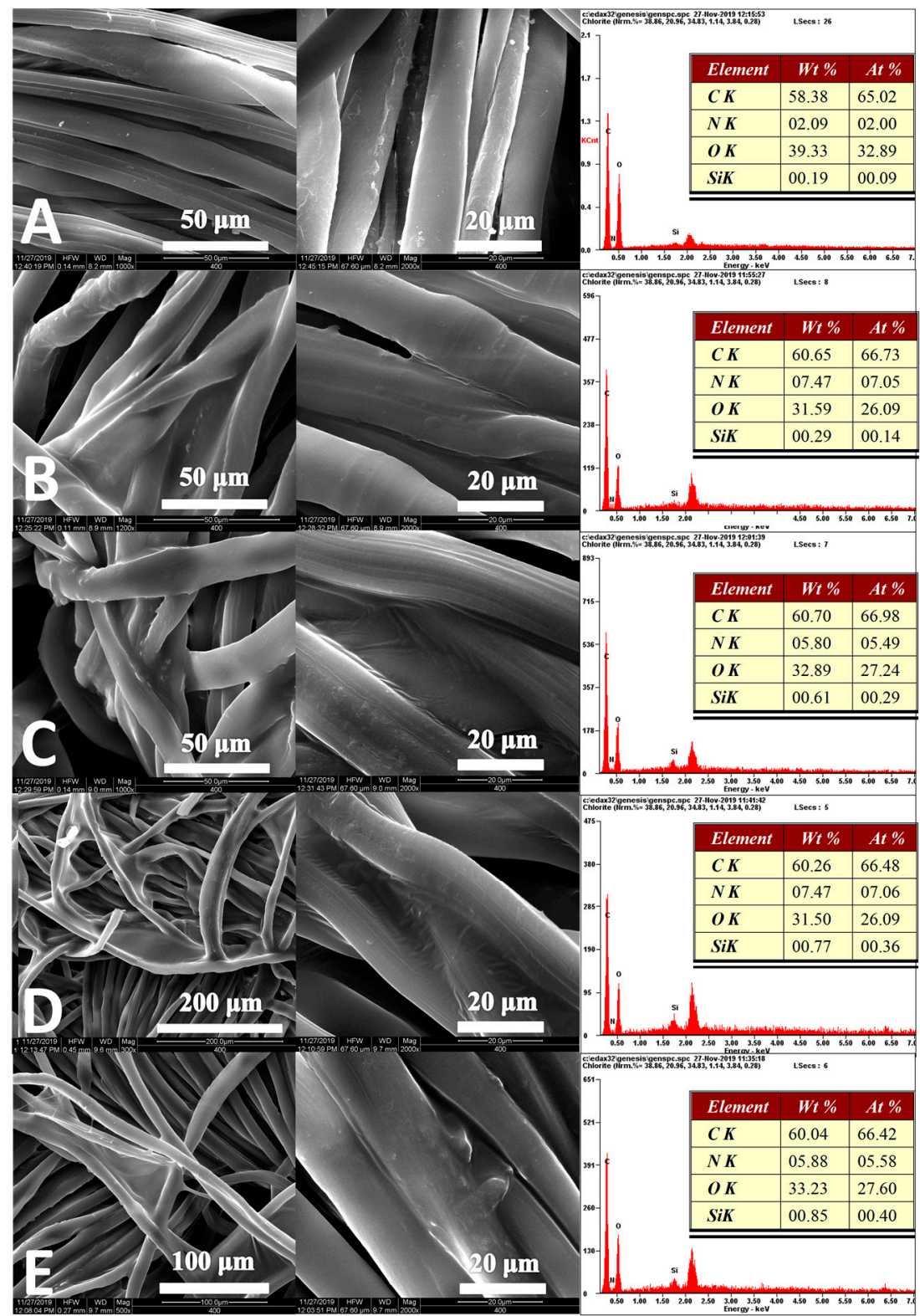

Figure 5. The representative SEM and EDS images of the (A) cotton textiles and the cotton textiles treated with (B) PUA, (C) SPUAI-5, (D) SPUAII-5, and (E) SPUAIII-5.

In order to evaluate its durability and reusability, the SPUAII-5-treated cotton textile was used to separate $\mathrm{n}$-hexane/water mixture repeatedly only with a drying process in $80^{\circ} \mathrm{C}$ in the oven for $10 \mathrm{~min}$ after each separation. The result shows that it still displays the good n-hexane/water separation property (Figure 6B(d)) after ten cycles. SPUAII-5-treated cotton textiles can also efficiently separate other oil/water mixtures such as cyclohexane/water and methylbenzene/water mixtures. However, it was found that the treated textile could not efficiently separate the liquid paraffin/water mixture (Figure $6 \mathrm{~B}(\mathrm{f})$ ), as the liquid paraffin has a relatively high viscosity. Therefore, this kind of treated cotton textiles is suitable to separate the mixture of water and some oils with low viscosities. 


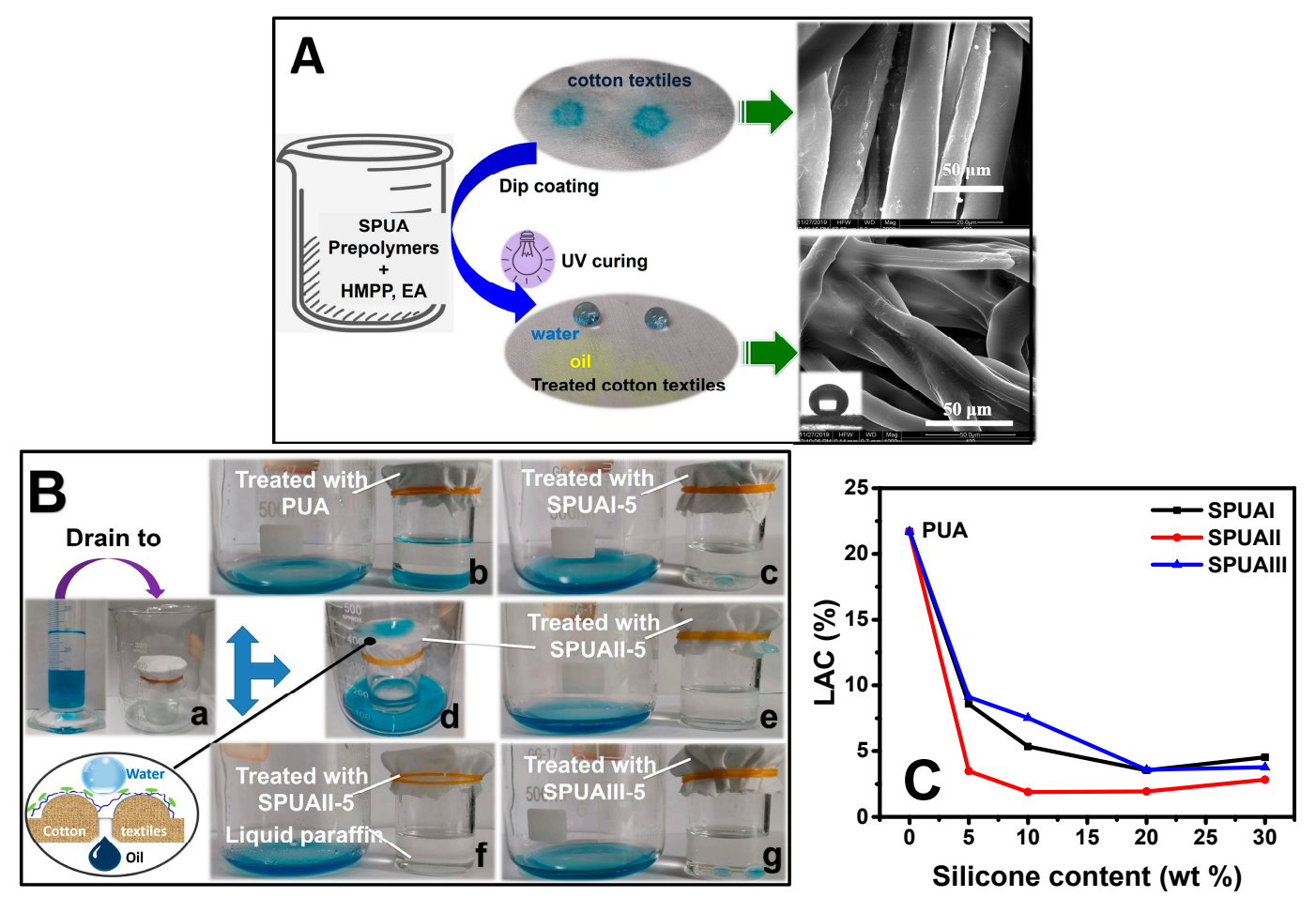

Figure 6. (A) Schematic illustration of the cotton textiles treatment process. (B) The device images for the oil/water separation process (a). The results of the n-hexane/water mixture separated with the treated cotton textiles by PUA (b), SPUAI-5 (c), SPUAII-5 (e), and SPUAIII-5 (g). The separation result of the 10th repeated separation of the n-hexane/water mixture with SPUAII-5-treated cotton textiles (d). The result of liquid paraffin-water mixture separated with SPUAII-5-treated cotton textiles (f). (C) The liquid absorption capacity (LAC) results for PUA- and SPUA-treated cotton textiles (the water for oil/water separation experiments were dyed with methylene blue).

\section{Conclusions}

In summary, three series of SPUA prepolymers with different silicone contents were synthesized successfully. The tris(trimethylsiloxy)silyl propyl side chains result in the decreased viscosity in SPUA prepolymers, implying less volatile organic solvents needed in future application for economic purpose. Then, the SPUA films were provided by the UV irradiation process.

To assess the properties influenced by the structures and dosages of silicone (MI-III), RT-IR, ATR-FTIR, SEM, EDS, WCA, TGA, DSC, water and hexane resistance, tensile testing, and LAC measurements were performed. The RT-IR results showed that a high content of acrylates and easy movement of polymer chains are helpful to obtain high DC values of SPUA. ATR-FTIR, DSC, and SEM demonstrated that tris(trimethylsiloxy)silyl propyl side chains could restrict the formation of hydrogen bonds, which would decrease the $T_{g}$ values and microphase separation degree of SPUA films. Moreover, relatively smooth surfaces were observed on the surfaces of SPUAII films, implying that phenyl groups have good compatibility with other segments. Obvious regular winkles also appeared on the surfaces of SPUAIII films (with tri-functional MIII), which are characterized by relatively high WCA values. From EDS analysis, the definite surface aggregation of side-chain silicone groups could bring about sufficient surface silicone segments with low silicone loadings. As expected, WCA and water and hexane resistance results implied the significantly improved hydrophobicity and lipophilicity of SPUA films (even containing $5 \mathrm{wt} \%$ silicone). From TGA and tensile testing, SPUA films with low silicone content are characterized by improved thermal stability and maintained mechanical properties. Noticeably, phenyl groups are helpful to improve the water resistance, tensile strength, and thermal stability from TGA and tensile testing of SPUA films. 
Furthermore, their applications in surface hydrophobic treatment of cotton textiles were investigated. It was shown that cotton fibres could be coated with SPUA films evenly and sufficiently by dip coating and UV curing. Moreover, phenyl groups and side-chain tris(trimethylsiloxy)silyl propyl groups are helpful to improve the hydrophobicity and lipophilicity of SPUA films. LAC analysis of treated cotton textiles, which is connected both with surface roughness and their chemical composition, indicated that relatively small LAC values of SPUAII treated cotton textiles should result from oleophilic phenyl groups and nonpolar silicone groups (consistent with previous water and hexane resistance analysis of SPUA films). Thus, SPUAII-5 (even with $5 \mathrm{wt} \% \mathrm{MII}$ )-treated cotton textiles can also efficiently separate oil/water mixtures such as cyclohexane/water and methylbenzene/water mixtures. Thus, it is shown that high crosslinking density, phenyl groups, and side-chain tris(trimethylsiloxy)silyl propyl groups are good for constructing hydrophobic treatment agents of SPUA. It provides a simple, cost-efficient, and environmentally friendly method to obtain hydrophobic cotton textiles with tremendous potential industrial applications such as in waterproofing and oil/water separation properties, among others.

Supplementary Materials: The following are available online at http://www.mdpi.com/2073-4360/12/8/1629/s1, Figure S1: FTIR Spectra of PUA, SPUAI (a), SPUAII (b) and SPUAIII (c) prepolymers, Table S1: The recipes for PUA and SPUAI-III with different silicone contents.

Author Contributions: Conceptualization, X.Y. and H.T; methodology, X.Y. and H.T.; software, X.Y.; validation, X.Y., Y.X. and H.T.; formal analysis, X.Y.; investigation, X.Y and H.T.; resources, X.Y. and H.T.; data curation, X.Y.; writing — original draft preparation, X.Y.; writing — review and editing, X.Y., Y.X. and H.T.; visualization, X.Y.; supervision, H.T. and Z.L.; project administration, H.T. and Z.L.; funding acquisition, H.T. and Z.L.. All authors have read and agreed to the published version of the manuscript.

Funding: This research was funded by the National Science Foundation of China $(21574101,21734007)$.

Acknowledgments: The financial support from the National Science Foundation of China $(21574101,21734007)$ is greatly appreciated.

Conflicts of Interest: The authors declare no conflict of interest.

\section{References}

1. Davis, R.; El-Shafei, A.; Hauser, P. Use of Atmospheric Pressure Plasma to Confer Durable Water Repellent Functionality and Antimicrobial Functionality on Cotton/Polyester Blend. Surf. Coat. Technol. 2011, 205, 4791-4797. [CrossRef]

2. Chen, K.; Gou, W.; Wang, X.; Zeng, C.; Ge, F.; Dong, Z.; Wang, C. UV-Cured Fluoride-Free Polyurethane Functionalized Textile with Ph-Induced Switchable Superhydrophobicity and Underwater Superoleophobicity for Controllable Oil/Water Separation. ACS Sustain. Chem. Eng. 2018, 6, 16616-16628. [CrossRef]

3. Ferrero, F.; Periolatto, M. Application of Fluorinated Compounds to Cotton Fabrics Via Sol-Gel. Appl. Surf. Sci. 2013, 275, 201-207. [CrossRef]

4. Tragoonwichian, S.; Kothary, P.; Siriviriyanun, A.; Edgar, A.; Yanumet, N. Silicon-Compound Coating for Preparation of Water Repellent Cotton Fabric by Admicellar Polymerization. Colloids Surf. Physicochem. Eng. Asp. 2011, 384, 381-387. [CrossRef]

5. Kim, T.; Kang, H.; Yoon, N. Synthesis of Non-Fluorinated Paraffinic Water Repellents and Application Properties on Textile Fabrics. Fiber. Polym. 2017, 18, 285-289. [CrossRef]

6. Park, Y.-B.; Im, H.; Im, M.; Choi, Y.-K. Self-Cleaning Effect of Highly Water-Repellent Microshell Structures for Solar Cell Applications. J. Mater. Chem. 2011, 21, 633-636. [CrossRef]

7. Hauser, J.; Zietlow, J.; Köller, M.; Esenwein, S.; Halfmann, H.; Awakowicz, P.; Steinau, H. Enhanced Cell Adhesion to Silicone Implant Material through Plasma Surface Modification. J. Mater. Sci. Mater. Med. 2009, 20, 2541. [CrossRef]

8. Yilgör, E.; Yilgör, I. Silicone Containing Copolymers: Synthesis, Properties and Applications. Prog. Polym. Sci. 2014, 39, 1165-1195. [CrossRef] 
9. Cho, E.-C.; Chang-Jian, C.-W.; Chen, H.-C.; Chuang, K.-S.; Zheng, J.-H.; Hsiao, Y.-S.; Lee, K.-C.; Huang, J.-H. Robust Multifunctional Superhydrophobic Coatings with Enhanced Water/Oil Separation, Self-Cleaning, Anti-Corrosion, and Anti-Biological Adhesion. Chem. Eng. J. 2017, 314, 347-357. [CrossRef]

10. Liu, H.; Wang, Z.; Sun, C. Robust Water-Repellent Treatment of Cotton Fabrics with Polysiloxane Modified Via Thiol-ene Click Reaction. Fiber. Polym. 2018, 19, 580-586. [CrossRef]

11. Li, K.; Zeng, X.; Li, H.; Lai, X.; Xie, H. Facile Fabrication of Superhydrophobic Filtration Fabric with Honeycomb Structures for the Separation of Water and Oil. Mater. Lett. 2014, 120, 255-258. [CrossRef]

12. Trepte, J.; Böttcher, H. Improvement in the Leaching Behavior of Dye-Doped Modified Silica Layers Coated onto Paper or Textiles. J. Sol-Gel Sci. Technol. 2000, 19, 691-694. [CrossRef]

13. Muzaffar, S.; Bhatti, I.A.; Zuber, M.; Bhatti, H.N.; Shahid, M. Synthesis, Characterization and Efficiency Evaluation of Chitosan-Polyurethane Based Textile Finishes. Int. J. Biol. Macromol. 2016, 93, 145-155. [CrossRef]

14. Azizi, N.; Ladhari, N.; Majdoub, M. Elaboration and Characterization of Polyurethane-Based Microcapsules: Application in Textile. Asian J. Text 2011, 1, 130-137. [CrossRef]

15. Fu, J.; Wang, L.; Yu, H.; Haroon, M.; Haq, F.; Shi, W.; Wu, B.; Wang, L. Research Progress of UV-Curable Polyurethane Acrylate-Based Hardening Coatings. Prog. Org. Coat. 2019, 131, 82-99. [CrossRef]

16. Jian, Z.; Yong, H.; Ming, X.; Jun, N. Preparation and Properties of Dual-Cure Polyurethane Acrylate. Prog. Org. Coat. 2009, 66, 35-39. [CrossRef]

17. Choi, S.-J.; Kim, H.N.; Bae, W.G.; Suh, K.-Y. Modulus-and Surface Energy-Tunable Ultraviolet-Curable Polyurethane Acrylate: Properties and Applications. J. Mater. Chem. 2011, 21, 14325-14335. [CrossRef]

18. Yu, Y.; Liao, B.; Li, G.; Jiang, S.; Sun, F. Synthesis and Properties of Photosensitive Silicone-Containing Polyurethane Acrylate for Leather Finishing Agent. Ind. Eng. Chem. Res. 2014, 53, 564-571. [CrossRef]

19. Najafi, F.; Bakhshandeh, E.; Hadavand, B.S.; Saeb, M.R. Toward UV-Curable Urethane Acrylate/Silica Hybrid Coatings: Introducing Urethane Methacrylate Trimethoxysilane (Uams) as Organic-Inorganic Coupling Agent. Prog. Org. Coat. 2014, 77, 1957-1965. [CrossRef]

20. Chen, W.-H.; Chen, P.-C.; Wang, S.-C.; Yeh, J.-T.; Huang, C.-Y.; Chen, K.-N. UV-Curable PDMS-Containing PU System for Hydrophobic Textile Surface Treatment. J. Polym. Res. 2009, 16, 601-610. [CrossRef]

21. Zhong, X.; Sheng, J.; Fu, H. A Novel UV/Sunlight-Curable Anti-Smudge Coating System for Various Substrates. Chem. Eng. J. 2018, 345, 659-668. [CrossRef]

22. Vuillequez, A.; Moreau, J.; Garda, M.; Youssef, B.; Saiter, J. Polyurethane Methacrylate/Silicone Interpenetrating Polymer Networks Synthesis, Thermal and Mechanical Properties. J. Polym. Res. 2008, 15, 89-96. [CrossRef]

23. Cheng, J.; Li, M.; Cao, Y.; Gao, Y.; Liu, J.; Sun, F. Synthesis and Properties of Photopolymerizable Bifunctional Polyether-modified Polysiloxane Polyurethane Acrylate Prepolymer. J. Adhes. Sci. Technol. 2016, 30, 2-12. [CrossRef]

24. Cheng, J.; Cao, Y.; Jiang, S.; Gao, Y.; Nie, J.; Sun, F. Synthesis and Performances of UV-curable Polysiloxane-Polyether Block Polyurethane Acrylates for PVC Leather Finishing Agents. Ind. Eng. Chem. Res. 2015, 54, 5635-5642. [CrossRef]

25. Yu, X.; Xiong, Y.; Zhou, C.; Li, G.; Ren, S.; Li, Z.; Tang, H. Polyurethane with Tris (Trimethylsiloxy) Silyl Propyl as the Side Chains: Synthesis and Properties. Prog. Org. Coat. 2020, 142, 105605. [CrossRef]

26. Decker, C.; Moussa, K. Real-Time Kinetic Study of Laser-Induced Polymerization. Macromolecules 1989, 22, 4455-4462. [CrossRef]

27. Podsiadły, R.; Strzelczyk, R. N-Substituted Quinoxalinobenzothiazine/Iodonium Salt Systems as Visible Photoinitiators for Hybrid Polymerization. Dyes. Pigments. 2013, 97, 462-468. [CrossRef]

28. Sheng, L.; Zhang, X.; Ge, Z.; Liang, Z.; Liu, X.; Chai, C.; Luo, Y. Preparation and Properties of Waterborne Polyurethane Modified by Stearyl Acrylate for Water Repellents. J. Coat. Technol. Res. 2018, 15, 1283-1292. [CrossRef]

29. Textiles. Test Methods for Nonwovens. Part 6: Absorption. ISO 9073-6:2003; International Organization for Standardization (ISO): Geneva, Switzerland, 2001.

30. Pourreau, D.B.; Smyth, S. New Low-Viscosity Acrylic-Urethane Prepolymers and Their Acrylated Oligomerse for Moisture and UV-Curable Coatings. Jct. Coatingstech. 2005, 2, 42-48.

31. Xu, S.; Xie, L.; Yu, X.; Xiong, Y.; Tang, H. Synthesis and Characterization of Phenyl Polysiloxane Modified Polyurea/polyurethanes. J. Polym. Sci. Pol. Chem. 2015, 5, 1794-1805. [CrossRef] 
32. Sun, F.; Shi, J.; Du, H.-G.; Nie, J. Synthesis and Characterization of Hyperbranched Photosensitive Polysiloxane Urethane Acrylate. Prog. Org. Coat. 2009, 66, 412-419. [CrossRef]

33. Hwang, H.-D.; Kim, H.-J. Enhanced Thermal and Surface Properties of Waterborne UV-Curable Polycarbonate-Based Polyurethane (Meth) Acrylate Dispersion by Incorporation of Polydimethylsiloxane. React. Funct. Polym. 2011, 71, 655-665. [CrossRef]

34. He, Y.; Zhou, M.; Wu, B.; Jiang, Z.; Nie, J. Synthesis and Properties of Novel Polyurethane Acrylate Containing 3-(2-Hydroxyethyl) Isocyanurate Segment. Prog. Org. Coat. 2010, 67, 264-268. [CrossRef]

35. Barszczewska-Rybarek, I.M. Quantitative Determination of Degree of Conversion in Photocured Poly (Urethane-Dimethacrylate) s by Fourier Transform Infrared Spectroscopy. J. Appl. Polym. Sci. 2012, 123, 1604-1611. [CrossRef]

36. Chattopadhyay, D.K.; Raju, K. Structural Engineering of Polyurethane Coatings for High Performance Applications. Prog. Polym. Sci. 2007, 32, 352-418. [CrossRef]

37. Tien, Y.I.; Wei, K.H. Hydrogen Bonding and Mechanical Properties in Segmented Montmorillonite/ polyurethane Nanocomposites of Different Hard Segment Ratios. Polymer 2001, 42, 3213-3221. [CrossRef]

38. Seymour, R.W.; Estes, G.M.; Cooper, S.L. Infrared Studies of Segmented Polyurethan Elastomers. I. Hydrogen Bonding. Macromolecules 1970, 3, 579-583. [CrossRef]

39. Hong, D.; Ryu, I.; Kwon, H.; Lee, J.-J.; Yim, S. Preparation of Superhydrophobic, Long-Neck Vase-Like Polymer Surfaces. PCCP 2013, 15, 11862-11867. [CrossRef]

40. Levine, F.; La Scala, J.; Kosik, W. Properties of Clear Polyurethane Films Modified with a Fluoropolymer Emulsion. Prog. Org. Coat. 2010, 69, 63-72. [CrossRef]

41. Wu, Z.; Wang, H.; Tian, X.; Cui, P.; Ding, X.; Ye, X. The Effects of Polydimethylsiloxane on Transparent and Hydrophobic Waterborne Polyurethane Coatings Containing Polydimethylsiloxane. PCCP 2014, 16, 6787-6794. [CrossRef]

42. Liang, J.; He, L.; Zhao, X.; Dong, X.; Luo, H.; Li, W. Novel Linear Fluoro-Silicon-Containing Pentablock Copolymers: Synthesis and Their Properties as Coating Materials. J. Mater. Chem. 2011, 21, 6934-6943. [CrossRef]

43. Liang, J.; He, L.; Dong, X.; Zhou, T. Surface Self-Segregation, Wettability, and Adsorption Behavior of Core-Shell and Pentablock Fluorosilicone Acrylate Copolymers. J. Colloid Interf. Sci. 2012, 369, 435-441. [CrossRef] [PubMed]

44. Zhang, Y.; Shang, J.; Lv, F.; Chu, P.K. Synthesis and Characterization of Novel Organosilicon-Modified Polyurethane. J. Appl. Polym. Sci. 2012, 125, 1486-1492. [CrossRef]

45. Park, M.S.; Cho, Y.H.; Kim, B.K.; Jang, J.S. Fabrication of Reflective Holographic Gratings with Polyurethane Acrylate (Pua). Curr. Appl. Phys. 2002, 2, 249-252. [CrossRef]

46. Ragesh, P.; Ganesh, V.A.; Nair, S.V.; Nair, A.S. A Review on 'Self-Cleaning and Multifunctional Materials'. J. Mater. Chem. A 2014, 2, 14773-14797. [CrossRef]

47. Li, X.-M.; Reinhoudt, D.; Crego-Calama, M. What Do We Need for a Superhydrophobic Surface? A Review on the Recent Progress in the Preparation of Superhydrophobic Surfaces. Chem. Soc. Rev. 2007, 36, 1350-1368. [CrossRef]

48. Li, Y.; Dai, S.; John, J.; Carter, K.R. Superhydrophobic Surfaces from Hierarchically Structured Wrinkled Polymers. ACS Appl. Mater. Inter. 2013, 5, 11066-11073. [CrossRef]

49. Oprea, S. Effect of Structure on the Thermal Stability of Curable Polyester Urethane Urea Acrylates. Polym. Degrad. Stab. 2002, 75, 9-15. [CrossRef]

50. Sultan, M.; Zia, K.M.; Bhatti, H.N.; Jamil, T.; Hussain, R.; Zuber, M. Modification of Cellulosic Fiber with Polyurethane Acrylate Copolymers. Part I: Physicochemical Properties. Carbohydr. Polym. 2012, 87, 397-404. [CrossRef]

51. Ghosh, T.; Karak, N. Silicone-Containing Biodegradable Smart Elastomeric Thermoplastic Hyperbranched Polyurethane. ACS Omega 2018, 3, 6849-6859. [CrossRef]

52. Hamdani-Devarennes, S.; Longuet, C.; Perrin, D.; Lopez-cuesta, J.-M.; Ganachaud, F. Flame Retardancy of Silicone-based Materials. Polym. Degrad. Stabil. 2009, 94, 465-495. [CrossRef]

53. Belva, F.; Bourbigot, S.; Duquesne, S.; Jama, C.; Le Bras, M.; Pelegris, C.; Rivenet, M. Heat and Fire Resistance of Polyurethane-polydimethylsiloxane Hybrid Material. Polym. Advan. Technol. 2006, 17, 304-311. [CrossRef] 
54. Hatakeyama, H.; Hirogaki, A.; Matsumura, H.; Hatakeyama, T. Glass Transition Temperature of Polyurethane Foams Derived from Lignin by Controlled Reaction Rate. J. Therm. Anal. Calorim. 2013, 114, 1075-1082. [CrossRef]

55. He, L.; Li, W.; Chen, D.; Zhou, D.; Lu, G.; Yuan, J. Effects of Amino Silicone Oil Modification on Properties of Ramie Fiber and Ramie Fiber/Polypropylene Composites. Mater. Des. 2015, 77, 142-148. [CrossRef]

56. Cho, T.K.; Chong, M.H.; Chun, B.C.; Kim, H.R.; Chung, Y.C. Structure-Property Relationship and Shape Memory Effect of Polyurethane Copolymer Cross-Linked with Pentaerythritol. Fiber. Polym. 2007, 8, 7-12. [CrossRef]

57. Chiou, B.S.; Schoen, P.E. Effects of Crosslinking on Thermal and Mechanical Properties of Polyurethanes. J. Appl. Polym. Sci. 2002, 83, 212-223. [CrossRef]

58. Liu, C.; Ma, C.; Xie, Q.; Zhang, G. Self-Repairing Silicone Coatings for Marine Anti-Biofouling. J. Mater. Chem. A 2017, 5, 15855-15861. [CrossRef]

59. Kaewpirom, S.; Kunwong, D. Curing Behavior and Cured Film Performance of Easy-to-Clean UV-Curable Coatings Based on Hybrid Urethane Acrylate Oligomers. J. Polym. Res. 2012, 19, 9995. [CrossRef]

60. Zhang, Y.; Zhan, F.; Shi, W. Photopolymerization Behavior and Properties of Highly Branched Poly (Thioether-Urethane) Acrylates Used for UV-Curing Coatings. Prog. Org. Coat. 2011, 71, 399-405. [CrossRef]

61. Lin, Y.H.; Chou, N.K.; Chen, K.F.; Ho, G.H.; Chang, C.H.; Wang, S.S.; Chu, S.H.; Hsieh, K.H. Effect of Soft Segment Length on Properties of Hydrophilic/Hydrophobic Polyurethanes. Polym. Int. 2007, 56, 1415-1422. [CrossRef]

62. Zhang, M.; Wang, C.; Wang, S.; Li, J. Fabrication of Superhydrophobic Cotton Textiles for Water-Oil Separation Based on Drop-Coating Route. Carbohydr. Polym. 2013, 97, 59-64. [CrossRef] [PubMed]

63. Fiedot-Toboła, M.; Ciesielska, M.; Maliszewska, I.; Rac-Rumijowska, O.; Suchorska-Woźniak, P.; Teterycz, H.; Bryjak, M. Deposition of Zinc Oxide on Different Polymer Textiles and Their Antibacterial Properties. Materials 2018, 11, 707. [CrossRef] [PubMed]

(C) 2020 by the authors. Licensee MDPI, Basel, Switzerland. This article is an open access article distributed under the terms and conditions of the Creative Commons Attribution (CC BY) license (http://creativecommons.org/licenses/by/4.0/). 